\title{
Erratum to: Increasing the laser damage threshold of the Nd:YAG crystal by ArF laser irradiation
}

\author{
S. Panahibakhsh ${ }^{1,2, a}$, S. Jelvani ${ }^{1}$, M.H. Maleki ${ }^{1}$, M. Mollabashi ${ }^{3}$, and M. Jaberi ${ }^{4}$ \\ 1 Laser and Optics Research Institute, Tehran, Iran \\ 2 Department of energy engineering and physics, Amirkabir University of Technology, Tehran, Iran \\ 3 Department of Physics, Iran University of Science and Technology, Tehran, Iran \\ ${ }^{4}$ Department of Physics, the University of Guilan, Rasht, Iran
}

Original article: Eur. Phys. J. Plus (2014) 129: 37, DOI: 10.1140/epjp/i2014-14037-y

Received: 25 May 2014

Published online: 31 July 2014 - C Società Italiana di Fisica / Springer-Verlag 2014

After publication of the paper, the authors have realized that the following corrections where needed.

- On page 3, second paragraph, last line, "to stimulate" should read "stimulated", i.e., the correct version of the paragraph is:

Increasing the lens focal length reduces statistical variability and allows a more accurate determination of the LIDT of materials. Thus, we used a $400 \mathrm{~mm}$ focal length lens with antireflection coatings on both surfaces. The spot size of the beam incident on the sample was $90 \pm 10 \mu \mathrm{m}$ diameters at $1 / e^{2}$ of the maximum intensity that is located $12 \mathrm{~mm}$ behind the front face of the sample to prevent surface damage and minimize the influence of self-focusing and stimulated Brillouin scattering (SBS). Damage locations were laterally separated by about $1 \mathrm{~mm}$.

- On pages 3 (fifth line from the bottom) and 4 (fourth line of the Conclusions), $302 \pm 25 \mathrm{~mJ} / \mathrm{cm}^{2}$ should be replaced by $302 \pm 35 \mathrm{~J} / \mathrm{cm}^{2}$.

\footnotetext{
${ }^{a}$ e-mail: panahi.spb@gmail.com
} 